\title{
Dukungan Keluarga pada Klien yang Mengalami Gangguan Jiwa di Wilayah Kerja Puskesmas Ulee Kareng Kota Banda Aceh
}

\author{
The Family Support Towart Psychiatric Clients at Coverage Area of The \\ Community Health Center of Ulee Kareng in Banda Aceh
}

\author{
Rusnita $^{1}$, Syarifuddin ${ }^{* 2}$ \\ ${ }^{1}$ Program Studi Ilmu Keperawatan, Fak. Kedokteran, Universitas Abulyatama, Jl. Blang Bintang Lama, Km, 8,3, Aceh Besar, \\ 23373, Indonesia \\ ${ }^{2}$ Program Studi Agribisnis, Fak. Pertanian, Universitas Abulyatama, Jl. Blang Bintang Lama, Km, 8,3, Aceh Besar, 23373 , \\ Indonesia \\ *Korespondensi Penulis: Syarifuddinhasan767@gmail.com
}

\begin{abstract}
Abstrak
Keluarga merupakan suatu jaringan interaksi antar pribadi. Keluarga berperan menciptakan persahabatan kecintaan, rasa aman hubungan antar pribadi yang bersifat kontinyu yang keseluruhanya merupakan dasar-dasar bagi perkembangan kepribadian anak. Salah satu perlindungan yang dilakukan oleh keluarga dalam kehidupan anggota-anggotanya adalah kesehatan, baik kesehatan jasmani maupun kesehatan rohani. Tujuan penelitian untuk mengetahui dukungan keluarga pada klien yang mengalami gangguan jiwa di wilayah kerja Puskesmas Ulee Kareng Kota Banda Aceh. Penelitian ini bersifat deskriptif eksploratif, populasi dalam penelitian ini 134 keluarga. Sampel berjumlah 57 keluarga, tempat penelitian wilayah kerja Puskesmas Ulee Kareng Kota Banda Aceh. Waktu penelitian 05 - 19 Juni 2018, instrumen penelitian yaitu kuesioner. Hasil penelitian dukungan instrumental kategori baik yaitu 36 responden $(63,2 \%)$, dukungan informasional kategori kurang baik yaitu 31 responden $(54,4 \%)$, dukungan penilaian pada kategori baik yaitu 36 responden $(63,2 \%)$, dukungan emosional pada kategori baik yaitu 35 responden $(61,4 \%)$, dukungan pada klien yang mengalami gangguan jiwa pada kategori baik yaitu 30 responden $(52,6 \%)$. Dapat disimpulkan bahawa dukungan instrumental kategori baik, dukungan informasional kategori kurang baik, dukungan penilaian pada kategori baik, dukungan emosional pada kategori baik, dukungan pada klien yang mengalami gangguan jiwa pada kategori baik.
\end{abstract}

Kata Kunci: Dukungan Keluarga, Gangguan Jiwa

\begin{abstract}
Family is a system of interpersonal interaction which role is to create friendship, love, and sense of security in continuous interpersonal relationship. In psychiatric phenomenon, that currently increases significantly every year in various part of world, family supports are genuinely needed. Moreover, there are about 450 million people in the world who suffer from mental disorder. In Indonesia alone, the prevalences of severe psychiatric prevalences of patients above 15 years old has reached the percentage of $0.46 \%$. This percentage means that there is more than 1 million people suffered from severe psychiatric issues in Indonesia. Of that number, $11.6 \%$ suffers from emotional psychiatric issues. As in Aceh, the data of Public Health Office in 2014 shows that the case of psychiatric issues has reached 18.741 patients
\end{abstract}


and only half of them were treated properly. Therefore, family supports including instrumental, informational, appraisal, and emotional support are significant factors in treating this case. The purpose of this research is to examine the family support toward psychiatric patients at the coverage area of Community Health Service of Ulee Kareng in Banda Aceh. The design of this research is explorative descriptive with a cross-sectional approach. The population of this research is 134 families. The sample is 57 families which determined by accidental sampling techniques. The research was conducted from June 5 to June 19, 2018. The research instrument is questionnaire. The research result indicates that there were 36 respondents $(63.2 \%)$ who received adequate instrumental support; 31 respondents $(54.4 \%)$ who received inadequate informational support; 36 respondents (63.2\%) who received adequate appraisal support; 35 respondents $(61.4 \%)$ who received adequate emotional support; and 30 respondents (52.6\%) who received adequate support toward mental disorder client. Therefore, this result indicates that the category of instrumental support is adequate, the category of informational support is inadequate, the category of appraisal support is adequate, the category of emotional support is adequate, and the category of support toward mental disorder client is adequate.

\section{Keywords: Family Support, Mental Disorder}

\section{PENDAHULUAN}

Salah satu fungsi keluarga adalah fungsi proteksi yaitu keluarga memberikan perlindungan dan perawatan baik fisik maupun sosial kepada para anggota, namun sekarang banyak fungsi perlindungan dan perawatan diambil alih oleh badan sosial. Keluarga merupakan suatu jaringan interaksi antar pribadi. Keluarga berperan menciptakan persahabatan kecintaan, rasa aman hubungan antar pribadi yang bersifat kontinyu yang keseluruhanya merupakan dasar-dasar bagi perkembangan kepribadian anak. Salah satu perlindungan yang dilakukan oleh keluarga dalam kehidupan anggota-anggotanya adalah kesehatan, baik kesehatan jasmani maupun kesehatan rohani (Fhitrishia, 2014).

Dalam sistem perawatan atau pengobatan, kesehatan, keluarga merupakan suatu pranata sosial yang melibatkan berbagai interaksi dalam masyarakat seperti pada penyembuhan pasien serta antara keluarga dengan lingkungan dimana ia berada untuk diikut sertakan dalam mengatasi penyakit yang diderita pasien. Peranan keluarga sangat dibutuhkan dalam proses pengobatan pasien gangguan jiwa, kondisi ini yang menyebabkan pentingnya peranan keluarga, karena keluarga merupakan kelompok kecil yang dapat berinteraksi dengan pasien, secara pribadi keluarga merupakan faktor utama dalam penyembuhan pasien. Dalam upaya pengobatan penyakit jiwa, keluarga berperan penting, karena keluarga mempunyai keterampilan khusus dalam menangani penderita gangguan jiwa, karena pada penderita penyakit jiwa ini penderita mengalami suatu kelemahan mental yang mana suatu keadaan terhenti atau tidak lengkapnya perkembangan pikiran yang mencakup gangguan makna 
intelegensia dan fungsi sosial disertai dengan pikiran tak bertanggung jawab serius atau agresif abnormal (Hamdani, 2012).

Dalam bidang kesehatan jiwa, batas jiwa yang sakit adalah derajat tingkah laku menjadi subtantif dan simbolis dengan cara yang tidak dapat dikehendaki dan derajat cara menghadapi masalah dengan cara neorotis dan rasional, dan tidak dengan cara yang rasional adanya fiksasi watak dengan keterbatasan-keterbatasannya terhadap aktualisasi diri yang menimbulkan gejala kehilangan atau kerusakan fungsi-fungsi yang sebelumnya ada berulang-ulang tingkah laku regresif dan distoris efek-efek memberi bukti adanya penyakit pada psikologi seseorang atau gangguan jiwa (Hidayat, Wahyu. 2006).

Saat ini dukungan dan penerimaan terhadap pasien gangguan jiwa oleh keluarga dan masyarakat di Provinsi Aceh masih sangat kurang, dimana banyak pasien gangguan jiwa yang sudah sembuh kurang bisa diterima oleh keluarga selama ini. Bahkan, ada pasien gangguan jiwa yang sudah sembuh, tidak mau dijemput pulang oleh keluarga mereka. Yang menjadi persoalan selama ini banyak pasien yang sudah sembuh secara medis tapi tidak sepenuhnya diterima oleh masyarakat. Imbasnya mantan pasien akan stres dan kembali sakit, mereka kembali lagi ke Rumah Sakit Jiwa.

Menurut (Friedman,2010), terdapat empat tipe dukungan keluarga yaitu informasional bantuan informasi yang disediakan agar dapat digunakan oleh seseorang dalam menanggulangi persoalan-persoalan yang dihadapi, meliputi pemberian nasehat, pengarahan, ide-ide. Instrumental keluarga sebagai tempat yang aman dan damai untuk bersistirahat dan juga menenangkan pikiran. Dukungan penilaian keluarga bertindak sebagai penengah dalam pemecahan masalah dan juga sebagai fasilitator dalam pemecahan masalah yang sedang dihadapi. Dukungan Emosional keluarga sebagai tempat yang aman dan damai untuk bersistirahat dan juga menenangkan pikiran. Setiap orang pasti membutuhkan bantuan dari keluarga.

Berdasarkan uraian permasalahan yang telah dikemukakan diatas maka peneliti tertarik untuk melakukan penelitian lebih dalam, tentang dukungan keluarga pada klien yang mengalami gangguan jiwa di wilayah kerja Puskesmas Ulee Kareng Kota Banda Aceh tahun 2018. Tujuan penelitian ini adalah ; untuk mengetahui dukungan keluarga pada klien yang mengalami gangguan jiwa diwilayah kerja Puskesmas Ulee Kareng Banda Aceh Tahun 2018. 


\section{METODE PENELITIAN}

Penelitian ini adalah deskriptif eksploratif yang dilakukan di keluarga pada klien yang mengalami gangguan jiwa di wilayah kerja Puskesmas Ulee Kareng kota kota Banda Aceh Tahun 2018 dengan jumlah populasi 134. Teknik pengambilan sampel, Simpel Random Sampling (Simple Random Sampling) dengan jumlah sampel 57 kepala keluarga.

\section{HASIL DAN PEMBAHASAN}

Dukungan keluarga kepada klien yang mengalami gangguan jiwa dari seluruh kriteria yang diteliti terdapat skor total 290 dengan rata-rata 51. Adapun jumlah frekuensi dapat dilihat pada tabel berikut:

Tabel 1. Distribusi Frekuensi Dukungan Keluarga pada Klien yang Mengalami Gangguan Jiwa di Wilayah Kerja Puskesmas Ulee Kareng Kota Banda Aceh Tahun 2018

\begin{tabular}{cccc}
\hline No. & Dukungan Keluarga & Frekuensi & Persentase \\
\hline 1. & Baik & 30 & 52,6 \\
2 & Kurang baik & 27 & 47,4 \\
\hline & Jumlah & $\mathbf{5 7}$ & $\mathbf{1 0 0 , 0}$ \\
\hline
\end{tabular}

Sumber: Data Primer Tahun (2018)

Berdasarkan Tabel.1 diketahui bahwa sebagian besar keluarga member dukungan pada klien yang mengalami gangguan jiwa pada kategori baik yaitu 30 responden $(52,6 \%)$ dan katagori kurang baik 27 responden $(47,4 \%)$.

\section{Pembahasan}

Dukungan Keluarga pada Anggota Keluarga yang Mengalami Gangguan Jiwa Hasil penelitian menggambarkan bahwa sebagian besar responden mendapatkan dukungan keluarga pada kategori baik 30 responden (52,6\%). Menurut konsep teoritis, sistem dukungan adalah segala fasilitas berupa dukungan yang diberikan kepada klien bersumber dari keluarga, teman, dan masyarakat di sekitarnya (Kemenkes R.I, 2013). Keluarga besar maupun keluarga inti berfungsi sebagai pendukung bagi anggota keluarganya. Peran keluarga berbeda-beda tergantung pada sifat bantuan yang diberikan dan jarak geografis yang jauh tidak menjadi halangan bagi anggota keluarganya (Irmansyah, 2009). Keluarga dan kerabat terdekat memiliki beberapa fungsi dukungan, yaitu: dukungan informasional, dukungan emosional, dukungan instrumental, dan dukungan penilaian (Padila 2012). 
Menurut peneliti, sudah baiknya seluruh dukungan keluarga karena sebagian besar klien adalah masih anggota keluarga inti atau kelarga dekat sehingga keluarga betul-betul memahami bagaimana keadaan perkembangan fisik, psikologi, sosial dan spiritual anggotanya termasuk klien dengan gangguan jiwa. Melalui keluarga yang memiliki ikatan darah dan tentu ikatan batin yang kuat akan sangat membantu klien untuk mendapatkan dukungan dan kebutuhan yang adekuat. Pendapat peneliti ini didukung oleh konsep teori yaitu ikatan keluarga yang kuat sangat membantu anggota keluarga yang mengalami trauma, hal ini dikarenakan anggota keluarga membutuhkan dukungan dari keluarganya (Padila 2012).

Sebuah studi menunjukkan bahwa terapi dukungan keluarga ini sangat efisien untuk menangani kondisi kejiwaan yang tidak menentu, stres traumatik dan efektif untuk mengatasi kecemasan serta gangguan psikologis lainnya. Model terapi dukungan ini mempunyai beberapa tujuan, yaitu: 1) Menambah kekuatan, keahlian, dan kemampuan klien dalam menggunakan sumber daya dalam dirinya. 2) Menurunkan tekanan/distres klien respon maladaptif lainnya. 3) Membantu untuk meningkatkan kemandirian klien, (Syamsudin, 2015).

\section{KESIMPULAN}

Berdasarkan hasil penelitian yang telah dilakukan, maka dapat disimpulkan sebagai berikut: Dukungan instrumental pada klien yang mengalami gangguan jiwa pada kategori baik sebanyak 36 responden (63,2\%). Dukungan informasional pada klien yang mengalami gangguan jiwa pada kategori kurang baik sebanyak 31 responden (54,4\%). Dukungan penilaian pada klien yang mengalami gangguan jiwa pada kategori baik sebanyak 36 responden $(63,2 \%)$. Dukungan emosional pada klien yang mengalami gangguan jiwa pada kategori baik sebanyak 35 responden $(61,4 \%)$. Dukungan keluarga dari seluruh kriteria diperoleh 30 responden $(52,6)$ memberikan dukungan yang baik terhadap anggota keluarga yang mengalami gangguan jiwa.

\section{SARAN}

Berdasarkan kesimpulan dari hasil penelitian di atas, maka dalam upaya meningkatkan mutu pelayanan kesehatan jiwa dalam keluarga di Wilayah Kerja Puskesmas Ulee Kareng Banda Aceh, maka peneliti memberikan saran sebagai berikut; membentuk tim khusus untuk merumuskan standar yang cocok untuk pedoman pelaksanaan kegiatan meningkatkan status kesehatan jiwa anggota keluarga yang mengalami gangguan jiwa, juga perlu membentuk Tim 
Penilai Status Kesehatan Jiwa dalam keluarga di wilayah kerja Puskesmas setempat untuk memonitor dan memotivasi staf puskesmas dan Kader dalam.

\section{DAFTAR PUSTAKA}

Fhitrishia, (2014). Peranan Keluarga Dalam Proses Pengobatan Pasien Gangguan Jiwa, Studi Kasus. Jurusan antropologi sosial. Fakultas Ilmu Sosial Dan Ilmu Politik Universitas Andalan. Padang.

Hamdani, (2012). Peranan Dukun Dalam Pengobatan Pasien Sakit Jiwa, Universitas. Andalas, Padang.

Hidayat, Wahyu. (2006). Skizofernia Pada Masyarakat Perantauan. Universitas Andalas, Padang,

Kemenkes R.I. (2013). Riset Kesehatan Dasar, Riskesdas 2013. Badan Penelitian dan Pengembangan Kesehatan. Jakarta

Padila (2012). Peran Dukungan Keluarga pada Penanganan Penderita Skizofrenia. Surakarta: Fakultas Psikologi Universitas Muhammadiyah, dipublikasikan. Rineka Cipta

Friedman, (2010). KeperawatanKeluarga: Riset Teori dan Praktek: alih bahasa, Achir Yani $\mathrm{S}$, Hami (et al): editor edisi bahasa Indonesia, Estu Tiar, Ed.5, Jakarta: EGC

Syamsudin. (2015). Dukungan Keluarga Terhadap Gejala kekambuhan Pasien Gangguan Jiwa yang berobat jalan. Jurnal Keperawatan. Akademi keperawata Karya Bhakti. Magelang

Irmansyah.(2009). Panduan Skizofrenia untuk Keluarga. Jakarta: Perhimpunan Jiwa Sehat "Indonesian Mental Health Association. 